\title{
58
}

\section{ON THE EXISTENCE OF DAILY CHANGES IN THE BACTERIAL NUMBERS IN AMERICAN SOIL}

\author{
H. G. THORNTON AND R. A. FISHER
}

\section{Rothamsted Experimental Station}

Received for publication May 6, 1926

The changing numbers of the various groups of microörganisms in a field soil must be a factor of vital importance to a proper understanding of the relationship of these organisms to their environment. It has long been known that the bacterial numbers are subject to seasonal changes. The numbers found at daily intervals has been studied recently by Cutler, Crump, and Sandon (2) at Rothamsted. These investigators found that in samples of soil taken at daily intervals from a plot on Barnfield, the bacterial counts obtained by the plate method showed striking variations from day to day. Before attributing these variations to true increases or decreases in the bacterial population counted, two possible sources of error must be considered.

In the first place there is a necessary experimental error in making the counts. In the work referred to, the platings were made by different workers, but in tests that were conducted, no variation in the technique could be detected, the factor limiting the accuracy of the counts being in nearly all cases the random distribution of the bacteria in the diluted suspension (4). This factor, which is calculable, was wholly insufficient to account for the fluctuations. The second source of error arises from the fact that samples taken at daily intervals are also taken at intervals in space, so that before the results are attributed to changes in bacterial numbers over a period of time, the possibility that they represent uneven distribution of the bacterial population in space must be excluded. This was done (2) by taking, on three occasions, 4 simultaneous samples from different parts of the plot. The counts obtained were in no case significantly different among the 4 samples. Furthermore, for 15 consecutive days, duplicate samples were taken 6 yards apart and the similar fluctuations in bacterial numbers were found in the duplicate series $(2$, p. 338). This rules out the possibility of accounting for the fluctuations found in Barnfield as being due to uneven distribution of the bacteria over the plot. Similar daily fluctuations in bacterial counts were found on Broadbalk (1) but there was no evidence as to whether the phenomenon was a general one occurring in other districts and under different soil conditions.

Recently, however, an important series of daily bacterial counts has been made at Washington, D.C., by Smith and Worden (6), who found fluctuations in the count from day to day. In this experiment, the plot salected was on a lawn, the sod of which was removed and the soil dug over 
The conditions were thus very different from those in the Rothamsted experiments. The method of sampling was also different, each count being made from a single core, instead of from a composite sample of 6 cores mixed together. Each day, however, the authors took 2 samples some distance apart and made separate counts from each, so that the influence on the results of the uneven distribution of the bacteria can be checked to some extent by comparing the variation in bacterial numbers between the 2 simultaneous samples with the difference found on consecutive days. The authors, on making such a comparison, concluded that the variation between simultaneous samples was greater than the fluctuations in the count from one day to the next. Their method of making this comparison is not valid, however, since they have compared the differences between individual simultaneous samples with day to day changes in the mean of 2 samples. Moreover, in sampling the plot, consecutive daily samples were taken from cores only 1 foot apart, whereas the 2 samples taken the same day were from spots several feet distant.

From the authors' data it is possible to make a decisive test of the reality of day to day changes in this particular set of counts, for if the whole of the variation observed in successive counts were due either to local differences or to the errors of random sampling, the two samples taken on the same day should show no positive correlation; indeed, since the simultaneous samples were taken from spots further apart than would be pairs chosen at random, a slight negative correlation should be anticipated. On the other hand, general changes in the bacterial numbers, affecting the whole plot, will tend to produce a positive correlation between simultaneous samples. If such a significant positive correlation between simultaneous samples exists, it excludes the possibility of the fluctuating bacterial counts being entirely due to uneven distribution of the bacteria. The authors' data are the more valuable because counts were made on 3 different media, namely, Löhnis' soil extract agar (5), Waksman's egg albumen agar (8), and Thornton's mineral salts agar (7). The counts on the first of these media from 32 pairs of samples taken between August 13 and September 19, show a positive correlation between simultaneous samples of +0.4955 . The egg albumen agar was used for only 19 pairs of simultaneous samples taken between August 28 and September 19, which show a positive correlation of +0.5673 . These two correlations must each be judged undoubtedly significant $(3$, p. 174). The mineral salts medium was similar to that employed by Cutler, Crump, and Sandon for the Barnfield counts, though the temperature and period of incubation were different from those used at Rothamsted. The results obtained on this medium are thus more nearly comparable with the Barnfield counts. On it the 32 pairs of simultaneous counts obtained show a positive correlation of +0.7744 . The probability against this occurring if the count differences were due to soil sample variation is about a million to one. Figures 1, 2, and 3 show the correlation between simultaneous samples on the three media. The existence of this correlation proves that the daily changes in the counts cannot be ascribed merely to uneven distribution of the bacteria within the area sampled. 
The correlations stated above do not exclude the effect of slow changes in the bacterial numbers from the beginning to the end of the observations, changes to which Smith and Worden call attention, and which might perhaps properly be called seasonal. The authors have, therefore, recalculated the three values, eliminating a linear term representing the steady increase (or decrease) in the numbers (3, p. 171). The results show that the association between counts made on the same day is not to any large extent attributable to seasonal changes, but that there remain substantial and significant correlations when

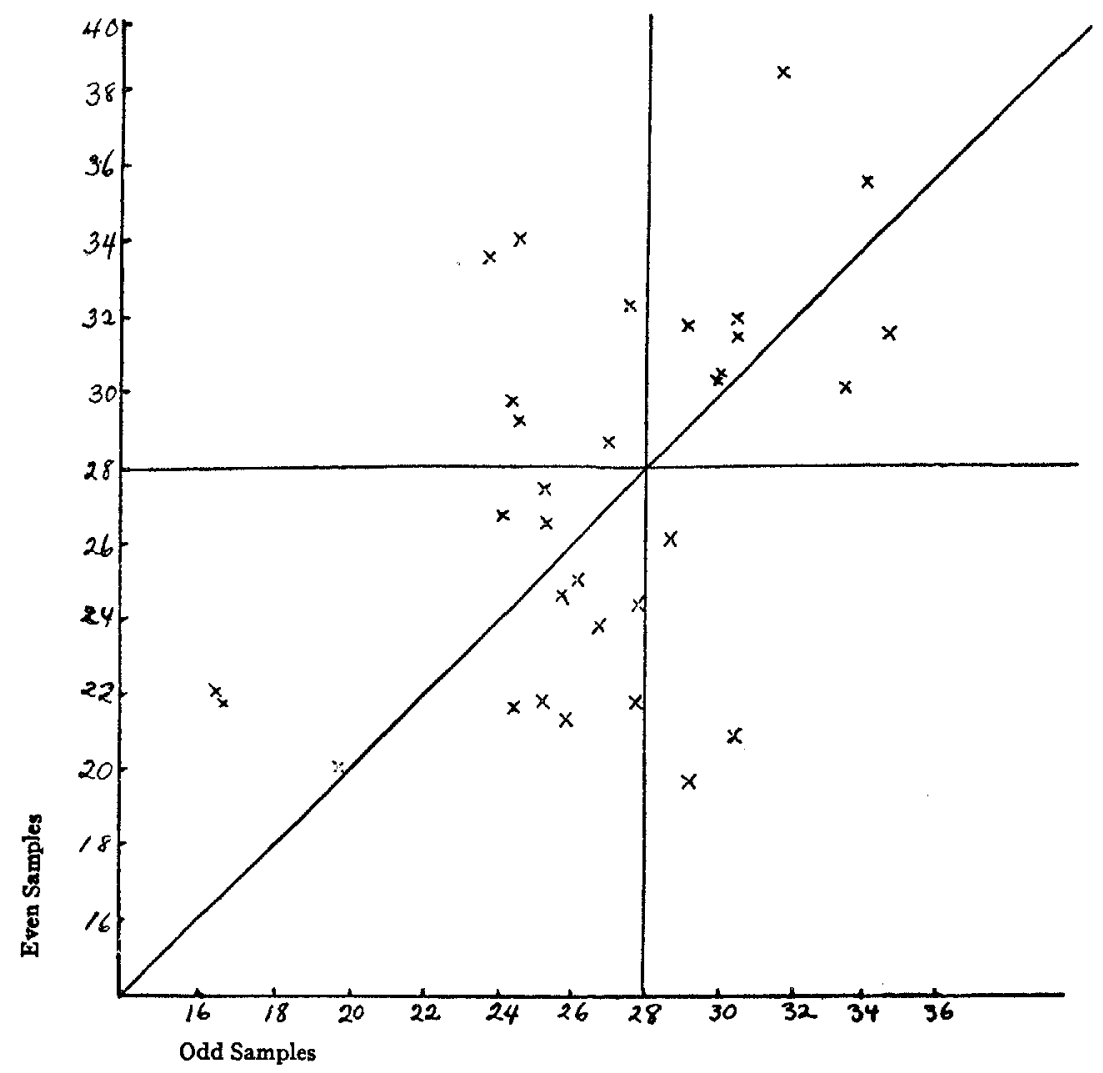

Fig. 1. Correlation between Simultaneous Samples Plated on Soir Extract agar

(Smith and Worden's data)

the seasonal effect is eliminated. For the soil extract medium the correlation is reduced to +0.3808 , a value which would occur by chance not more than once in 20 trials. For the egg albumen medium the correlation has risen to +0.6615 and for the mineral salts agar it has fallen to +0.7060 , both these values being of quite unquestionable significance.

In speaking of the counts published by Smith and Worden as affording confirmation in American soil of continual changes similar to those observed at Rothamsted, it should be stated that we have never lost sight of the fact that systematic variations from day to day in the manipulative technique might 
in many ways simulate actual variations in the bacterial population. In the case of the work at Rothamsted, the particular observations upon which our conclusions are based, as well as the whole body of comparable routine observations, have been so thoroughly tested and confirmed as to leave no residuum of doubt as to the objective reality of the phenomenon. Obviously, in the case of work done elsewhere, we have no such direct evidence of uniform technique and we can only demonstrate the existence of day to day variations of the same type as those observed at Rothamsted, without excluding the

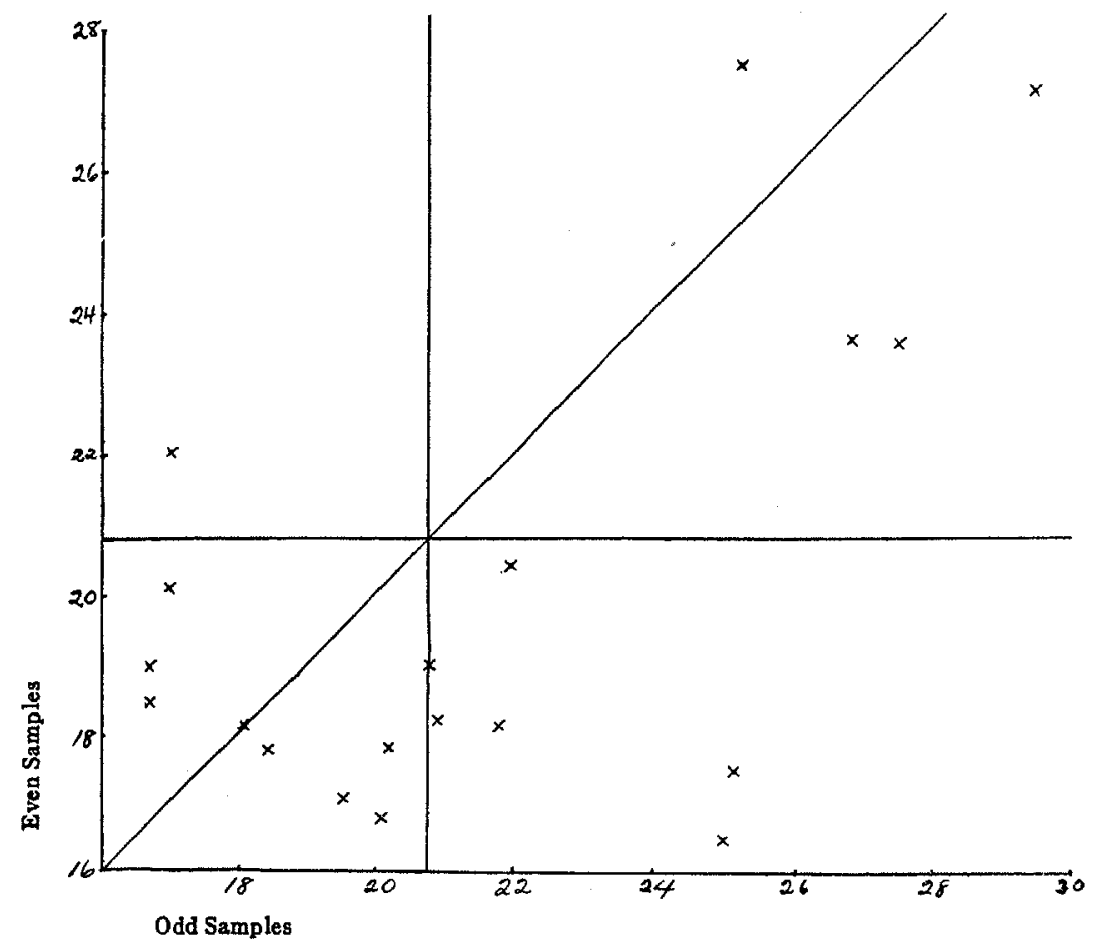

Fig. 2. Correlation between Stmultaneous Samples Plated on Egg Albumen Agar (Smith and Worden's data)

possibility that variations in technique may have contributed to, or may be responsible for, the variations observed.

It is interesting that the closest correlation between counts from simultaneous samples was found when the mineral salts medium was used. If the counts obtained on this medium from individual cores be plotted separately (fig. 4) it is seen how similar are the changes in numbers in different regions of the plot. The fluctuations are more apparent on this medium than on either of the other media. The authors are probably right in attributing this to the selective action of the mineral salts medium. When using the plate method there is never any question of obtaining total bacterial counts, because no single 
medium can possibly allow all physiological groups of the bacteria to develop. Consequently the comparative number of colonies that develop from a soil plating on a given medium is no criterion of the value of that medium for invastigation. On the other hand it is essential to a satisfactory technique that

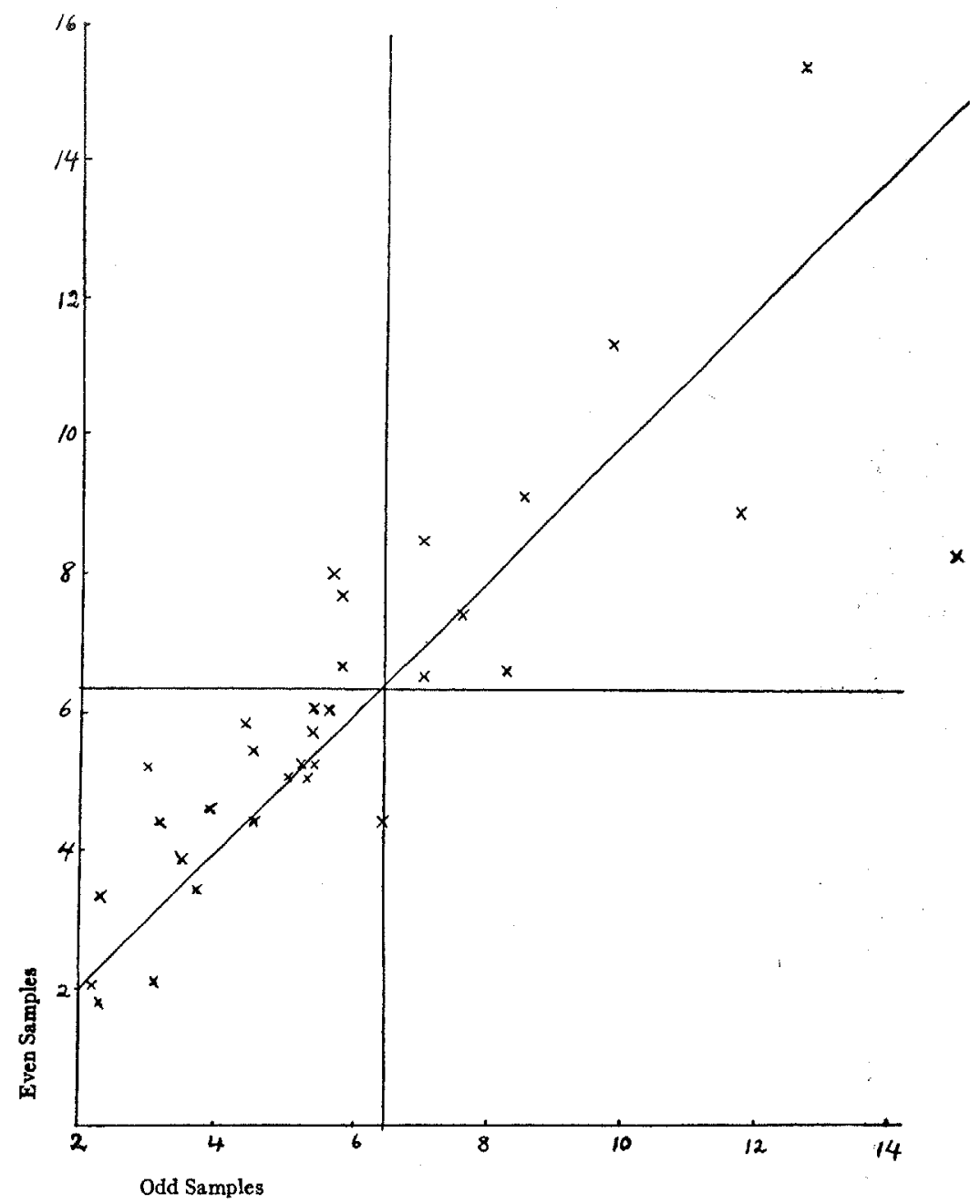

Fig. 3. Correlatton between Simultaneous Samples Plated on Mineral Satts agar (Smith and Worden's data)

the agreement between parallel plates should justify the assumptions upon which the dilution method is based, as can be tested by calculating $\chi^{2}(4)$, and this agreement has so far been demonstrated only with the mineral salts agar. The greater number of colonies that appeared on the soil extractmedium probably indicates, as is suggested by Smith and Worden, that it is a 
less selective medium than the mineral salts agar. For this reason it is less appropriate to the present type of investigation. It is unlikely that the numbers of all groups of bacteria fluctuate simultaneously. Some groups will increase while others will diminish in numbers. Consequently a selective medium is best suited to the study of these fluctuations because it diminishes the chance that a fall in the numbers of one group will be obscured on the plate counts by the increase of another group.

The work of Smith and Worden thus indicates that daily fluctuations in the state of the bacterial population which are similar in type to those already found at Rothamsted, exist in American soil, and also that the fluctuations occur under widely different soil conditions. There can be little doubt that the phenomenon is of general occurrence. It is possible, however, that only under exceptional conditions will the soil be sufficiently uniform to permit of its easy detection.

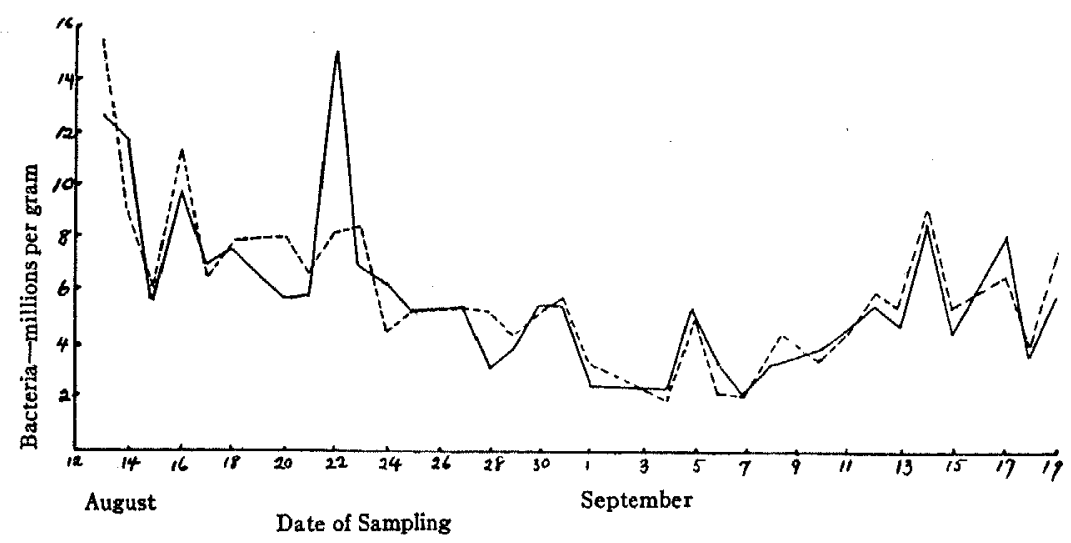

Fig. 4. Daily Counts on Mineral Salts Medium data.)

Bacterial numbers from the duplicate samples separately plotted. (Smith and Worden's SUMMARY AND ABSTRACT

The daily bacterial counts published by Smith and Worden show variations which cannot be explained by unequal distribution of bacteria in the soil, or by seasonal changes in bacterial numbers.

On all three media employed by them, significant positive correlations in bacterial numbers between simultaneous samples were obtained.

The similar daily fluctuations occurring in different parts of the plot show most clearly on Thornton's mineral salts medium.

Provided the manipulative technique of Smith and Worden was sufficiently uniform, the results afford evidence of the existence, in very different conditions, of fluctuations in bacterial numbers similar to those observed at Rothamsted. 


\section{REFERENCES}

(1) CUTLER, D. W., AND Crump, L. M, 1920 Daily periodicity in the numbers of active soil flagellates with a brief note on the relation of trophic amoebae and bacteria numbers. Ann. Appl. Biol. 7: 11-24.

(2) Cutler, D. W., CRUMP, L. M., AND SANDON, H. 1922 A quantitative investigation of the bacterial and protozoan population of the soil with an account of the protozoan fauna. Phil. Trans. Royal Soc. (B) 211: 317-350.

(3) Frsher, R. A. 1925 Statistical Methods for Research Workers. Oliver and Boyd, Edinburgh.

(4) Fisher, R. A., Thornton, H. G., and Mackenzie, W. A. 1922 The accuracy of the plating method of estimating the density of bacterial population with particular reference to the use of Thornton's agar medium with soil samples. Ann. Appl. Biol. 9: 325-359.

(5) LöHNIs, F. 1913 Laboratory Methods in Agricultural Bacteriology. Philadelphia.

(6) SMrrt, N. R., AND WORDEN, S. 1925 Plate Counts of Soil Microörganisms. Jour. Agr. Res. 31: 501-517.

(7) Trornton, H. G. 1922 On the development of a standardized agar medium for counting soil bacteria with especial regard to the repression of spreading colonies. Ann. Appl. Biol. 9: 241-247.

(8) Waksman, S. A. 1921 Microbiological analysis of soil as an index of soil fertility: II. Methods of the study of numbers of microörganisms in the soil. Soil Sci. 14: 283-298. 